\title{
PRIVACIDADE E AUTONOMIA DE UM ADULTO COM DEFICIÊNCIA INTELECTUAL
}

\author{
Geovana Silva Wertonge \\ Universidade Federal de Santa Maria \\ geovana-wertonge@hotmail.com \\ Sabrina Fernandes de Castro \\ Universidade Federal de Santa Maria \\ sabrinafcastro@gmail.com \\ Gabriela Brutti Lehnhart \\ Universidade Federal de Santa Maria \\ gabilehnhart@gmail.com
}

Recepción Artículo: 16 mayo 2021

Admisión Evaluación: 16 mayo 2021

Informe Evaluador 1: 12 mayo 2021

Informe Evaluador 2: 23 mayo 2021

Aprobación Publicación: 01 junio 2021

\section{RESUMO}

No presente estudo, buscou-se conhecer os aspectos relacionados a Privacidade e Autonomia na vida de um adulto com deficiência intelectual, bem como analisar se interferem na execução das atividades de vida doméstica, de vida comunitária e aprendizagem ao longo da vida. Dessa forma, utilizou-se como abordagem a pesquisa estudo de caso. Participaram da pesquisa um adulto (38 anos) com deficiência intelectual (DI) e sua mãe (63 anos). Tendo em vista a situação de pandemia do COVID-19, no ano de 2020/2021, a pesquisa foi realizada por meio da plataforma Google Meet, tendo três fontes de dados: a Escala de Intensidade de Apoios (SIS), aplicação | (2019) e || (2020), entrevista semi-estruturada aplicada com 0 adulto com DI e Protocolo de Observação Participante. Com isso, através da análise dos resultados do estudo, destaca-se a ocorrência de oportunidades do adulto expor seus sentimentos, planos futuros e desejos, quando a mãe não estava presente nos encontros. Em relação aos níveis de apoio em atividades que demandam Privacidade e Autonomia em relação a três domínios da SIS: vida doméstica, vida comunitária e aprendizagem ao longo da vida, foi evidenciado nos dados da aplicação II da SIS, uma diminuição dos índices de necessidade de apoio nos três domínios. Portanto, evidencia-se a importância de trabalhar as questões de Autonomia, Privacidade, Autodeterminação e Auto advocacia, no desenvolvimento de pessoas com DI na vida adulta.

Palavras-chave: educação especial; deficiência intelectual; privacidade; autonomia; autodeterminação

\section{ABSTRACT}

The privacy and autonomy of an adult with intellectual disability. This study aimed to know the aspects related to Privacy and Autonomy in the life of an Adult with intellectual disability and analyze if they inter- 


\section{PRIVACIDADE E AUTONOMIA DE UM ADULTO COM DEFICIÊNCIA INTELECTUAL}

fere in home living, community living, and lifelong learning. Thus, the case study research method was used on a 38-year-old adult with intellectual disability (ID) and his 63-year-old mother. The study was carried out using Google Meet and three sources of data: the Support Intensity Scale (SIS) with applications I (2019) and II (2020), a semi-structured interview applied with the adult with ID, and Participant Observation Protocol. Our findings showed that the occurrence of opportunities for the adult to express his feelings, future plans, and desires, when the mother was absent from the meetings, stands out. Regarding the levels of support in the activities of Privacy and Autonomy via the three SIS domains (home living, community living, and lifelong learning), a decrease in the need for support was evidenced in the application II data. Therefore, the importance of working on the issues of Autonomy, Privacy, Self-determination, and Self-advocacy is evident in the growth of Adults with ID.

Keywords: special education; intellectual disability; privacy; autonomy; self-determination

\section{INTRODUÇÃO}

Compreende-se que por muitos anos as pessoas com deficiência intelectual não ocupavam um lugar na sociedade. Essas questões podem ser percebidas no próprio histórico da deficiência intelectual, na exaltação do julgamento da incapacidade desses sujeitos, sem viver uma vida de qualidade com autonomia nas atividades cotidianas. Bissoto (2014) alerta para atribuição a baixa capacidade mental dada a pessoa com deficiência intelectual por meio dos comportamentos da sociedade e 0 fator da concepção da deficiência intelectual historicamente estar ligada a um padrão de anormalidade no desenvolvimento, a partir disso supõe-se que esses sujeitos exigem controle e tutela, não havendo possibilidades de educação para a autonomia .As autoras Veltrone \& Mendes (2009) apontam que a discussão sobre o contexto educacional e sua influência, na produção da deficiência intelectual, esteve bastante presente nos estudos que enfatizavam o fracasso escolar. Neles, 0 aluno era considerado com deficiência intelectual quando era inserido na escola e não acompanhava o currículo escolar. As autoras citadas anteriormente, destacam que após a classificação, identificação e categorização, condições foram impostas ao aluno com deficiência intelectual, bem como os espaços de ensino segregado foram desenvolvidos.

Segundo Thompson et al (2004, p.9) "0s adultos com deficiência intelectual não eram encorajados a assumir riscos". Com isso, a importância da reflexão sobre as possibilidades de intervenções funcionais para adultos com deficiência intelectual, pois permite apontar uma compreensão da dimensão dessas oportunidades. Tendo em vista a necessidade de alteração das propostas infantis para atividades correspondente com as suas idades cronológicas, caracterizando, assim, as questões relacionadas a autonomia (ou falta dela).Atualmente quando nos referimos a sujeitos com deficiência intelectual, procura-se uma definição para o termo, que historicamente vem sofrendo mudanças tanto em relação a sua terminologia, bem como sobre as interpretações acerca da sua própria definição, muitas vezes enfatizando o que 0 indivíduo pode ou não vir a fazer em decorrência da sua deficiência. 0 conceito de deficiência intelectual utilizado nesse estudo, é o constituído pela Associação Americana de Deficiência Intelectual e do Desenvolvimento - AAIDD (2010), que define a deficiência intelectual por meio de limitações significativas no funcionamento intelectual e no comportamento adaptativo, abrangendo as habilidades sociais, práticas e conceituais, devendo ocorrer antes dos 18 anos de idade. Recentemente a AAIDD (2021) realizou uma atualização da definição de deficiência intelectual, enfatizando aspectos como: a avaliação considerando a diversidade cultural e linguística, bem como as diferenças de comunicações, sensoriais, motoras e comportamentais; limitações devem ser consideradas dentro do contexto de ambientes comunitários típicos da idade e da cultura do indivíduo; e 0 desenvolvimento de um perfil de necessidades de apoio para 0 indivíduo (AAIDD, 2021, p.1)

Com isso, para que se estabeleçam possibilidades na educabilidade de adultos com deficiência intelectual é necessário pensar no tipo de apoio que esses precisam para desenvolver novas potencialidades a partir de suas necessidades visando sua autonomia em atividades funcionais. A AAIDD (2021) define os apoios como as estratégias e recursos que buscam promover o desenvolvimento e os interesses de uma pessoa melhorando, assim, o funcionamento individual e o bem-estar pessoal. Almeida (2004)-aponta quatro níveis de apoio: 1) Intermitente, 
caracterizado por ser oferecido conforme a necessidade da pessoa (alta ou baixa intensidade) e de forma episódica; 2) Limitado, sua intensidade de apoio é consistente ao longo do tempo; 3) Amplo, o apoio é oferecido regularmente e sem tempo limitado; e 4) Permanente, apoio de alta intensidade e constante. A AAIDD (2021) aponta, também, sete componentes importantes, que envolvem estratégias de apoio, para o planejamento e implementação dos apoios, quais sejam: 1) Naturais: construir, ou manter, as redes de apoio (família, amigos, pares e colegas); incentivar a auto advocacia, promover o envolvimento na comunidade e engajamento social (incluindo estabelecer amizades); 2) Tecnológicos: por meio do uso de dispositivos para auxiliar na comunicação (incluindo comunicação alternativa), para manter a saúde e o bem-estar, ou qualquer outro dispositivo eletrônico que melhore o funcionamento do indivíduo no seu dia-a-dia; 3) Protéticos: são componentes artificiais com o objetivo de suprir necessidades funcionais do corpo, fornecem apoios sensoriais ou assistência motora; 4) Aprendizagem ao Iongo da vida: capacidade de desenvolver novas habilidades e comportamentos por meio de treinamento ou oportunidades de aprendizagem; 5) Habitação condigna: espaços seguros e acessíveis (inclui moradia, transporte e espaço de trabalho), espaços que favoreçam a circulação e desempenho das tarefas de forma autônoma; 6) Respeito e Dignidade: Oportunidades, reconhecimento, valorização, independência financeira, auto advocacia, gerenciamento de metas e tomada de decisões visando a melhoria do papel social e envolvimento na comunidade em que vive; 7) Qualidades pessoais: Destacando as preferências individuais, objetivos e metas pessoais, tomada de decisão, motivação, atitudes positivas e estratégias de auto advocacia e autodefesa.

Nesse sentido, a necessidade de planejamento de apoios, de propor intervenções, que favoreçam o desenvolvimento da autonomia desses sujeitos. Mas, antes, faz-se extremamente necessário conhecer o sujeito. Como um potencial instrumento para o planejamento de apoio temos a Escala de Intensidade de Apoios (SIS) ${ }^{1}$ (posteriormente será descrita), que tem como objetivo medir a intensidade da necessidade de apoio de pessoas com deficiência intelectual, fornecendo para educadores, profissionais e instituições informações necessárias para 0 planejamento centrado na pessoa.

Para esse estudo, faz-se necessário entender o conceito de autonomia. Esse conceito pode ser encontrado com diferentes concepções e perspectivas nos campos da filosofia, política ou bioética. Contudo, a autonomia aqui discutida está na possibilidade do sujeito fazer escolhas em sua vida, assim como, pretende-se enfatizar juntamente a autodeterminação e privacidade. Santos (2015, p. 17) enfatiza que "A autonomia é tanto a capacidade de fazer sozinho ações diárias como a capacidade de decisão de escolha". Bissoto (2014) aponta que o processo de tomada de decisões está simultaneamente ligado à nossa qualidade de vida. A autora ainda cita alguns exemplos de tomadas de decisões que deveriam ser executadas pelas pessoas com deficiência intelectual, por exemplo, o engajamento na sua auto advocacia, a escolha de um relacionamento amoroso, rumos de sua vida sexual, opções vocacionais, entre outros. Embora essas decisões sejam complexas, elas devem ser executadas e proporcionadas, por meio de estratégias no ensino de sujeitos com DI. No que tange a questão da privacidade, nesse estudo, pressupõe-se suas questões objetivam enfatizar o espaço que o indivíduo necessita, para assim, desenvolver sua autonomia e autodeterminação a partir de escolhas para o seu futuro e qualidade de vida. La Taille (1999) aponta que a privacidade é um elemento que marca os limites entre o sujeito e o outro, assim como, 0 espaço de intimidade entre sujeito e o espaço público.

Logo, o intuito do processo de promoção da autonomia e privacidade para os sujeitos com deficiência intelectual precisa ser amparado por propostas que objetivamente possam abranger o modo como eles vivem na sociedade atual e local, considerando os seus direitos e deveres dentro desse contexto. Nesse contexto, ora apresentado surge o presente estudo que teve como objetivo conhecer os aspectos relacionados a Privacidade e autonomia na vida de um Adulto com deficiência intelectual, bem como analisar se interferem na execução das atividades de vida doméstica, vida comunitária e aprendizagem ao longo da vida, foi desenvolvido no ano de 2020 com um adulto com deficiência intelectual e sua mãe. 0 sujeito foi escolhido por estar matriculado em um curso técnico de uma universidade federal de um município de médio porte no Estado do Rio Grande do Sul/Brasil. A escolha desses três domínios (vida doméstica, vida comunitária e aprendizagem ao longo da vida) surgiram da demanda do sujeito durante a avaliação inicial e das sugestões apontadas por ele e por sua mãe. 


\section{PRIVACIDADE E AUTONOMIA DE UM ADULTO COM DEFICIÊNCIA INTELECTUAL}

\section{METODOLOGIA}

Relata-se que esse estudo foi desenvolvido a partir de um vínculo com o projeto de mestrado intitulado "Gestão de Habilidades Sociais para estudantes com Deficiência Intelectual no Contexto da Educação Profissional e Tecnológica", sob a autoria da pesquisadora Lehnhart (2020)². Nesse contexto, a pesquisa que ora relata-se foi desenvolvida em parceria com o projeto de mestrado, visto que se utilizou dos encontros individuais de um dos sujeitos para a coleta de dados. No que tange aos encontros semanais com 0 adulto escolhido, foram realizados 21 encontros, com duração de uma hora, no período de junho à dezembro de 2020. Em cada um dos encontros desenvolveu-se uma temática, como exemplo: Perfil Profissional, Comunicação, Rotina, Diário semanal, Tutoriais, Calendário acadêmico, Habilidades sociais, Atividades de vida comunitária - diálogos em locais públicos, Assuntos de interesse do estudante e Atividades de vida doméstica. Como as aulas do curso técnico do sujeito da pesquisa passaram a ser remotas, por conta do distanciamento social ocasionado pela pandemia, ouve crescente necessidade de acesso a ambientes virtuais de aprendizagem, como Moodle, e de comunicação, a exemplo da plataforma Google Meet, assim entendeu-se a necessidade de desenvolvimento de tutoriais personalizados para acesso de forma independente a esses espaços de aprendizagem.

\section{Cuidados éticos}

Antes do início da pesquisa os participantes foram informados de todos os procedimentos, riscos e benefícios, ficando de livre escolha a participação. Em seguida, ocorreu a assinatura do Termo de Consentimento Livre e Esclarecido pela participante (mãe do adulto) e do Termo de Assentimento pelo participante (adulto com DI). Salienta-se, que foi entregue uma cópia desses Termos os participantes com os contatos das pesquisadoras para esclarecimento de quaisquer dúvidas, a qualquer tempo. Os procedimentos metodológicos da pesquisa foram submetidos ao Comitê de Ética em Pesquisa com seres humanos (CEP) da Universidade Federal de Santa Maria tendo recebido parecer favorável para a sua realização (Lehnhart, 2021).

\section{Local}

Devido a atual situação (2020/2021) de distanciamento social imposta pela pandemia do Coronavírus (COVID-19), a pesquisa foi realizada de maneira 100\% remota em um ambiente virtual. Com isso, foi escolhida a plataforma Google Meet, que é um serviço de comunicação por vídeo chamada desenvolvido pelo Google.

\section{Participantes da pesquisa}

0 estudo constitui-se de dois participantes. 0 primeiro participante é um adulto de 38 anos com deficiência intelectual, por motivos éticos será identificado pelo codinome de Cacto, estudante de um curso subsequente da Educação Profissional e Tecnológica em uma Universidade pública localizada em um município de médio porte, no estado do Rio Grande do Sul, Brasil. A segunda participante é a mãe de Cacto, 63 anos, identificada pelo codinome de Violeta.

\section{Instrumentos}

Para este estudo foram utilizadas três fontes de coleta de dados. A primeira fonte de dados foi a Escala de Intensidade de Apoios -SIS-A (Thompson et al., 2004). A SIS-A organiza-se em três seções, a Seção 1 -Escala de Necessidades de Apoio consiste em 49 atividades divididas em seis domínios: vida doméstica, vida comunitária, aprendizagem ao longo da vida, emprego, saúde e segurança e sociais. Por conseguinte, apresenta-se a Seção 2- Escala Suplementar de Proteção e Defesa por meio de 8 atividades. Já a terceira e última seção Necessidades Específicas de Apoio Médico e Comportamental, é dividida em 15 condições médicas e 13 condutas comportamentais. Nas seções 1 e 2 para que seja realizada a avaliação de cada parte e item, é necessário seguir uma chave de pontuação que é conduzida através de três medidas de necessidade de suporte: 1) tipo de apoio, 2) frequência e 3) tempo diário. 0 tipo de apoio é relacionado a natureza do apoio necessário para a realização de uma atividade, seguindo uma escala de 0-4 onde marca-se nenhum (0), monitoramento (1), pistas ver- 
bais (2), ajuda física parcial (3) e ajuda física total (4). A frequência questionará quantas vezes em uma escala de 0-4 0 apoio é proporcionado. 0 tempo diário reflete a quantidade de tempo que 0 apoio necessário é dado para a realização de uma atividade em um dia típico, em uma escala de 0-4.

Para que seja realizada a avaliação de cada um dos itens da seção 3 , indica-se uma escala de 0-2. A indicação do número 0 (não necessita de apoio),1 (necessita de algum apoio, ex:supervisão) e 2(necessita de muito apoio). A Escala foi aplicada em dois momentos, a aplicação I foi realizada em 2019 e a aplicação II em 2020, tendo sido respondida concomitantemente pelo adulto e sua mãe. Os resultados da Escala foram utilizados como base para a elaboração dos demais instrumentos da pesquisa.

A segunda fonte de dados, foi a entrevista semi-estruturada com 0 adulto com deficiência intelectual. Os questionamentos da Entrevista semi-estrutura foram resultantes dos dados do nível de necessidade de apoio avaliados na aplicação I, abrangendo três domínios da Escala SIS escolhidas para serem observadas nesse estudo, atividades da vida doméstica (ex. "preparar o alimento", "cuidar e limpar a casa", "utilizar aparelhos eletrônicos", etc.), vida comunitária (ex. "deslocamento de um local para o outro na comunidade", "visitar amigos e familiares", "ir às compras", etc.) e aprendizagem ao longo da vida (ex. "interagir com outras pessoas em atividades de aprendizagem", "participar nas decisões sobre a própria educação e formação", "utilizar a tecnologia para aprender"; "acessar contextos educacionais", etc..). A escolha das três seções deu-se pela demanda de necessidade de apoio expostas pelo adulto e sua mãe durante a aplicação da SIS no ano de 2019.

A seguir na tabela 1, serão apresentados os questionamentos realizados na entrevista para cada um dos três domínios pesquisados:

Tabela 1. Questionamentos da Entrevista Semi-estruturada

\begin{tabular}{|c|c|}
\hline Domínio & Questionamentos \\
\hline $\begin{array}{l}\text { Atividades de vida } \\
\text { doméstica }\end{array}$ & $\begin{array}{l}\text { Com quem você mora? } \\
\text { Você divide seu quarto com outra pessoa? } \\
\text { Você prepara seu alimento (ex: café da manhã, almoço, jantar, } \\
\text { algum lanche)? } \\
\text { Você arruma seu quarto? } \\
\text { Você organiza a casa? } \\
\text { Você esquenta sua comida no micro-ondas? }\end{array}$ \\
\hline $\begin{array}{l}\text { Atividades de vida } \\
\text { comunitária }\end{array}$ & $\begin{array}{l}\text { Como você vai para a Universidade? } \\
\text { Você utiliza transporte público para seu deslocamento até a } \\
\text { Universidade? } \\
\text { Você vai ao cinema? (ex: passeio, ir à igreja, shopping, } \\
\text { cinema) } \\
\text { Em que lugares você vai sozinho? Onde gostaria de ir } \\
\text { sozinho? } \\
\text { Você visita seus amigos e familiares? Costuma ir sozinho ou } \\
\text { com outras pessoas? }\end{array}$ \\
\hline $\begin{array}{c}\text { Atividades de } \\
\text { aprendizagem ao longo } \\
\text { da vida }\end{array}$ & $\begin{array}{l}\text { Como foi realizada a escolha do curso? } \\
\text { Qual a disciplina do curso você mais gosta? } \\
\text { O que pretende fazer depois que terminar o curso? } \\
\text { Como você costuma se comunicar com seus } \\
\text { amigos/familiares/colegas/professores (entre outros)? } \\
\text { Quando você chega à um local público (se necessário, dar } \\
\text { exemplos) e encontra outras pessoas. O que você faz? } \\
\text { O que você faz quando alguém lhe faz um favor? Qual sua } \\
\text { reação? (ex: ganha algo, presente) } \\
\text { Você já teve algum relacionamento? Como } \\
\text { acontecia/acontece a comunicação? }\end{array}$ \\
\hline
\end{tabular}

A terceira fonte de dados compõe-se de um protocolo de observação participante, teve como finalidade avaliar a privacidade adulto com deficiência intelectual em cada um dos 21 encontros virtuais. É dividido em duas partes: 1) Protocolo Adulto e 2) Protocolo Mãe, que são compostas pelos itens: número, data, horário, duração, temática, ocorrência e observações. Para 0 item da ocorrência, existiu um objetivo diferente para cada um dos 


\section{PRIVACIDADE E AUTONOMIA DE UM ADULTO COM DEFICIÊNCIA INTELECTUAL}

participantes. 0 protocolo 1 avaliou o comportamento do adulto nos encontros em relação a presença da mãe, a legenda da ocorrência foi marcada pelos numerais: 0 (nenhum descontentamento, 1 (descontentamento verbal em relação a presença da mãe), 2 (descontentamento visual em relação a presença da mãe) e 3 (descontentamento visual e verbal em relação a presença da mãe). 0 Protocolo 2, avaliou a ocorrência do comportamento da mãe, a legenda da ocorrência, também, aconteceu por meio dos numerais: 0 (não esteve presente), 1 (presente no encontro) e 2 (presente e respondendo perguntas sem ser demandada).

\section{Procedimento de coleta de dados}

Primeiramente foi realizado um primeiro contato com o adulto com deficiência intelectual, objetivando uma apresentação pessoal e convite para a sua participação nos encontros virtuais. Após esse primeiro contato, foram realizados vinte e um (21) encontros semanais de forma virtual, pelo Google Meet, uma vez na semana e com duração de uma hora. Uma vez que, esses encontros foram temáticos, a entrevista semi-estruturada foi aplicada durante esses momentos, através de perguntas sincronizadas com as temáticas dos encontros. Por exemplo, na temática sobre as atividades de vida comunitária, surgiu a pergunta de como 0 adulto desloca-se até a Universidade. Além disso, nesses encontros virtuais, ocorreu a observação participante. Os encontros foram gravados com a permissão dos participantes do estudo.

\section{Procedimento de análise dos dados}

Para análise dos dados, nessa pesquisa, foi adotada a abordagem de análise qualitativa e quantitativa. Em relação aos resultados da Escala SIS-A, aplicação I e aplicação II foi realizada a análise quantitativa das necessidades de apoio de cada uma das seções do instrumento. Os dados da SIS-A foram organizados em uma planilha do Software Excel, com o objetivo de identificar e possibilitar uma análise da intensidade de necessidade de apoio do Adulto com DI antes (Aplicação I) e pós (Aplicação II) os encontros virtuais. No protocolo de observação participante, a análise também foi quantitativa, analisando a ocorrência e o número de encontros que aconteceram os comportamentos dos participantes. Os dados foram apresentados por meio de gráficos no Software Excel, uma vez que foi possível identificar quantas oportunidades ( $n^{0}$ de encontros) ocorreram e quantas/quais ocorrências aconteceram em cada um dos encontros. E por último, na entrevista semi-estruturada com 0 adulto, foi realizada uma análise qualitativa das respostas.

\section{ANÁLISE E DISCUSSÃO DOS RESULTADOS}

Os resultados obtidos nessa pesquisa apresentam os dados dos índices de necessidade de apoio através da Escala SIS, dados da Entrevista semi-estruturada com o adulto com DI, e os dados das ocorrências do comportamento do adulto e mãe durante os encontros por meio do Protocolo de Observação Participante.

Sendo assim, o Protocolo de Observação Participante, dividido entre duas partes 1) Protocolo Adulto tendo as ocorrências determinadas a partir de uma pontuação de 0-3 e 0 2) Protocolo Mãe determinadas por meio de uma pontuação de 0-2. Nas Tabelas 2 e 3 é possível verificar as ocorrências em cada um dos protocolos e a quantidade de encontros que elas aconteceram:

Tabela 2. Comportamento de Cacto nos encontros virtuais

\begin{tabular}{c|c}
\hline OCORRÊNCIA & ENCONTROS \\
\hline Nenhum descontentamento & 2 (Perfil Profissional e Tutorial) \\
\hline $\begin{array}{c}\text { Descontentamento verbal em } \\
\text { relação a presença da mãe }\end{array}$ & 2 (Vídeo (curso técnico) e Encontro com os \\
estudantes I) \\
\hline $\begin{array}{c}\text { Descontentamento visual em } \\
\text { relação a presença da mãe }\end{array}$ & 1 (Comunicação) \\
\hline $\begin{array}{c}\text { Descontentamento verbal e } \\
\text { visual em relação a presença da } \\
\text { mãe }\end{array}$ & $\begin{array}{c}\text { 6 (Treinamento para evento I, Treinamento para } \\
\text { evento II, Rotina, Diário, Encontro com os } \\
\text { estudantes II e Participação evento) }\end{array}$ \\
\hline
\end{tabular}


Tabela 3. Comportamentos da Violeta nos encontros virtuais

\begin{tabular}{c|c}
\hline OCORRÊNCIA & ENCONTROS \\
\hline $\begin{array}{c}\text { Não esteve presente } \\
\text { no encontro }\end{array}$ & $\begin{array}{c}10 \text { (Apresentação, Encontro com os estudantes II, Calendário } \\
\text { acadêmico, Encontro com os estudantes III, Habilidades } \\
\text { Sociais, Atividades de vida comunitária, Assuntos de interesse } \\
\text { do estudante, Rotina II, Atividades de vida doméstica e } \\
\text { Calendário/dezembro). }\end{array}$ \\
\hline Presente no encontro & $\begin{array}{c}7 \text { (Perfil Profissional, Comunicação, Encontro com o } \\
\text { estudantes I, Rotina I, Diário, Tutorial e Encontro com os } \\
\text { estudantes IV) }\end{array}$ \\
\hline $\begin{array}{c}\text { Presente e } \\
\text { respondendo } \\
\text { perguntas sem ser } \\
\text { demanda }\end{array}$ & $\begin{array}{c}\text { 4 (Vídeo (curso técnico), Treinamento I, Treinamento II e } \\
\text { Participação evento) }\end{array}$ \\
\hline
\end{tabular}

A exemplo de descontentamento verbal em relação a presença da mãe podemos destacar que Cacto demostrava impaciência e ansiedade quando Violeta respondia perguntas por ele, solicitando que a mãe não respondesse as perguntas que ele deveria responder. Sobre descontentamento visual em relação a presença da mãe, destaca-se a fuga do olhar e mudança de semblante com a aproximação da responsável, algumas vezes colocava a mão no rosto (simbolizando sentir-se envergonhado). E ainda, sobre o descontentamento verbal e visual, existiram 0 conjunto de comportamentos já citados acima, como exemplo: colocava a mão no rosto e ao mesmo tempo pedia para que a mãe 0 deixasse responder as perguntas ou não falasse quando seria ele quem deveria demostrar opiniões ou escolhas.

Nos encontros em que a Violeta não esteve presente, Cacto sentia-se mais à vontade para expressar e relatar suas angústias do ensino remoto, desejos para o futuro, relações interpessoais e suas atividades da rotina. Diante disso, torna-se importante relatar que Violeta foi construindo, por meio de dicas verbais das pesquisadoras, a consciência e importância de deixar o filho sozinho durante os encontros. Outro fator, foi o desenvolvimento de Cacto em relação a autonomia no acesso a plataforma do Google Meet, não precisando mais do apoio de Violeta no acesso, conduzindo a uma privacidade durante os encontros.

Na sequência, serão apresentadas seis figuras que ilustram os dados coletados. As cores apresentadas nas figuras, correspondem a tríade: tipo, frequência e tempo de apoio, ambas chaves de pontuação da SIS-A, uma vez que nas figuras a ajuda física total (4) é representada pela cor vermelha, ajuda física parcial (3) na cor cinza, pistas verbais ou gestuais (2) pela cor amarelo, monitoramento (1) na cor azul e nenhum tipo de apoio (0) na cor verde. Assim, quanto mais verde estiver nas figuras, indica maior autonomia do sujeito na realização das atividades. A seguir, na Figura 1 (Aplicação I) e na Figura 2 (Aplicação II) os resultados dos dados da Escala SIS-A, referente ao domínio da vida doméstica. 


\section{PRIVACIDADE E AUTONOMIA DE UM ADULTO COM DEFICIÊNCIA INTELECTUAL}

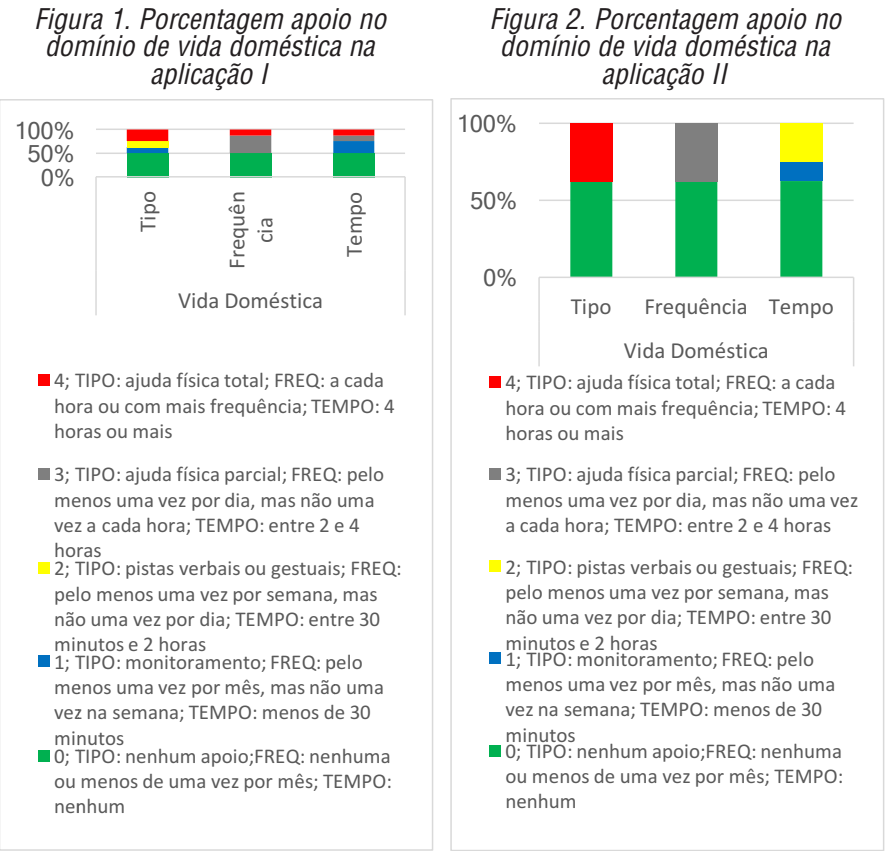

Os dados referentes ao domínio vida doméstica são representados por oito atividades, a saber: Utilizar o banheiro; cuidar da roupa; preparar o alimento; alimentar-se; cuidar e limpar a casa; vestir-se; tomar banho; cuidar da higiene e cuidados pessoais; utilizar aparelhos eletrônicos, observa-se que a aplicação I apresentava uma média de 50\% de necessidade de algum apoio (total, parcial, verbal, gestual ou monitoramento) e na aplicação II esse índice caiu para 38\%. Demostrando que na aplicação II mais de 60\% das atividades de vida domésticas são realizadas de forma independente. Sabe-se que quanto menor 0 índice de necessidade de apoio, maior a autonomia do sujeito com DI. Vejamos um exemplo, durante a entrevista, quando questionado sobre usar apareIhos domésticos ou preparar seu alimento, Cacto respondeu: "Não, a mãe que faz ou a senhora que mora conosco faz antes de eu e a mãe acordar. Eu não chego perto do fogão porque eu não quero ter problema (...)". Na fala de Cacto, percebe-se que a dependência em atividades domésticas pode ser resultado de falta de oportunidade para desempenhar as funções.

Durante os encontros, Cacto relatava atividades diferentes realizadas com maior autonomia, a exemplo de limpeza e manutenção do seu quarto. Evidencia-se, então, a importância de que aconteçam intervenções com a mãe e 0 ensino sobre como proporcionar momentos de autonomia e independência nas atividades de vida doméstica para Cacto. A autora Boueri (2010) teve como um de seus objetivos desenvolver a independência nas atividades de vida diária em jovens com deficiência intelectual institucionalizados. Para isso, ocorreram algumas intervenções com as atendentes desse espaço institucionalizado, de forma que elas pudessem promover 0 apoio aos residentes (jovens com DI) sem limitar o desempenho das atividades de forma autônoma. Sendo assim, foi observado que houve mudanças comportamentais no decorrer das intervenções, proporcionando a independência na realização das atividades, mesmo que algumas atendentes discorressem sobre a insegurança de que os residentes não conseguissem aprender as atividades.

A seguir, serão apresentados na Figura 3 (Aplicação I) e Figura 4 (Aplicação II) os resultados dos dados da Escala SIS-A, referente ao domínio da vida comunitária. 

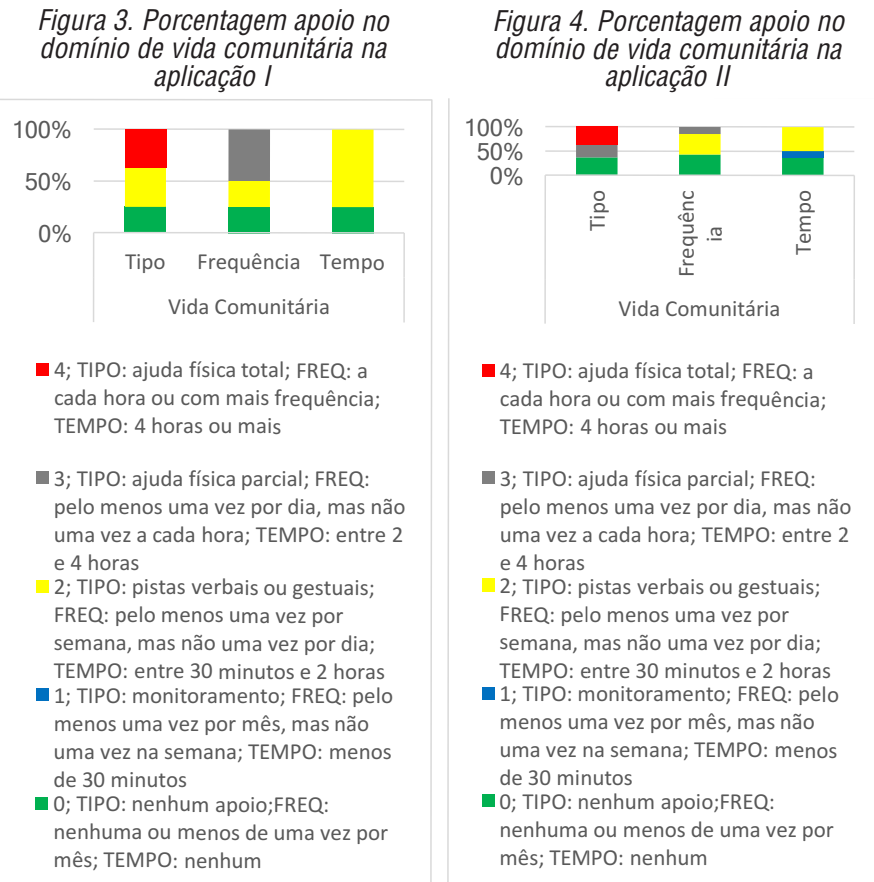

Os dados do domínio de vida comunitária são representados por oito atividades: Deslocar-se de um local para o outro na comunidade, utilizando ou não transporte; participar em atividades de recreação e lazer na comunidade; visitar amigos e familiares; participar em atividades de sua preferência na comunidade; ir às compras, adquirir produtos e contratar serviços; interagir com pessoas da comunidade e frequentar locais públicos. Os dados do domínio de atividades de vida comunitária evidenciam que na aplicação I havia $75 \%$ de necessidade de apoio (total, parcial, verbal, gestual ou monitoramento) e na aplicação II ocorreu uma diminuição para 63\%. Na entrevista, Cacto respondeu a questões sobre já ter ido sozinho em espaços da sua comunidade e se teria algum local que tem vontade de ir sozinho: "Eu já fui sozinho na (nome da papelaria) aqui de (nome do bairro que reside), uma vez eu fui sozinho, porque a mãe me pediu um favor pra mim ir lá buscar umas coisas no (nome do mercado)".Violeta relatou que Cacto nunca vai sozinho aos lugares do seu bairro, sua justificativa é o medo do filho atravessar a rua bastante movimentada perto da residência da família e na maioria das vezes que Cacto desloca-se na comunidade é acompanhado por uma pessoa. Zutião (2016) observou em seu estudo a grande insegurança e medo por parte dos responsáveis em relação a exploração por parte de pessoas estranhas ocasionada a seus filhos. Justificando, se assim, a dificuldade de proporcionar oportunidades de independência em atividades de vida na comunidade, mesmo considerando que são sujeitos adultos e que as atividades são em seu contexto comunitário. Zutião (2016) concluiu que existe muita insegurança por parte da família das pessoas com deficiência, no que tange, a deixá-los buscar sua independência em atividades que possam Ihe causar algum risco.

Abaixo na Figura 5 (Aplicação I) e Figura 6 (Aplicação II) os resultados dos dados da Escala SIS-A, referente ao domínio de aprendizagem ao longo da vida. 


\section{PRIVACIDADE E AUTONOMIA DE UM ADULTO COM DEFICIÊNCIA INTELECTUAL}

Figura 5. Porcentagem apoio no domínio de aprendizagem ao longo da vida na aplicação I.

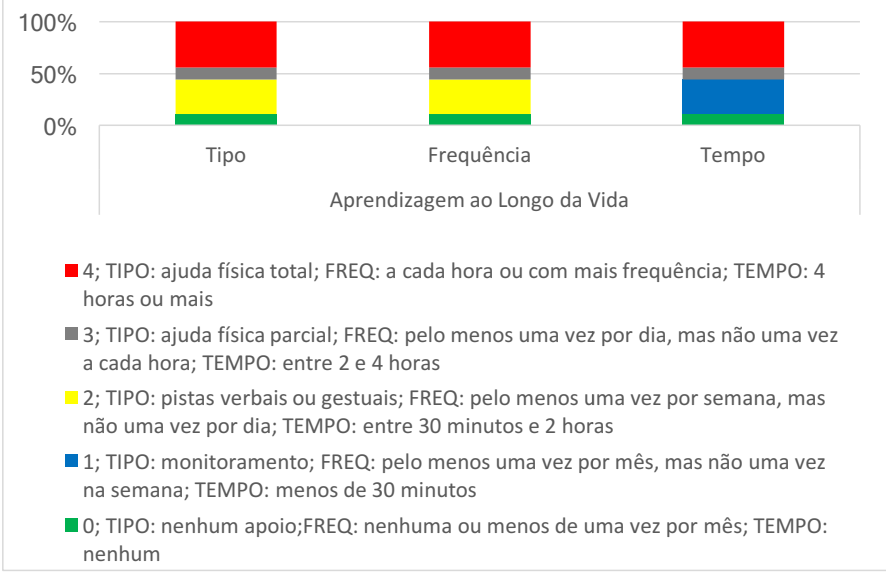

Figura 6. Porcentagem apoio no domínio de aprendizagem ao longo da vida na aplicação II.

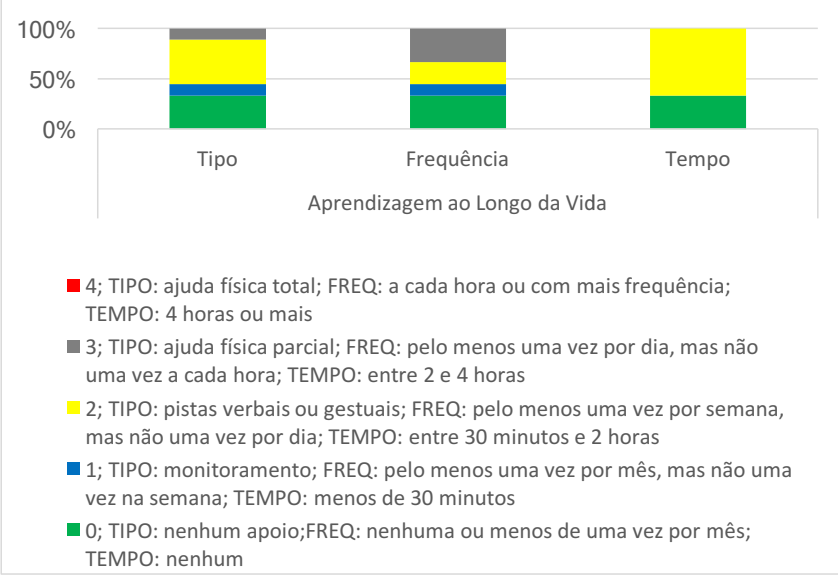

0 domínio aprendizagem ao longo da vida é constituído por nove atividades: Interagir com outras pessoas em atividades de aprendizagem; participar nas decisões sobre a própria educação e formação; aprender e usar estratégias para a resolução de problemas; utilizar a tecnologia para aprender; acessar contextos educacionais e de formação; aprender competências acadêmicas funcionais; aprender habilidades para a saúde e atividades físicas; aprender habilidades de autodeterminação e aprender estratégias de autogerenciamento. Os resultados das atividades de aprendizagem ao longo da vida apresentam uma maior diminuição da necessidade de algum apoio (total, parcial, verbal, gestual ou monitoramento), uma vez que na aplicação I eram 89\% e na aplicação II 67\%.

Atualmente Cacto não necessita de ajuda física total em nenhuma das nove (9) atividades do domínio de aprendizagem ao longo da vida. Destaca-se as atividades que apresentaram mudanças mais significativas no tipo de apoio: 1) Participar nas decisões sobre a própria educação e formação (Aplicação I = ajuda física total versus Aplicação II= pistas verbais ou gestuais) ; 2) Utilizar a tecnologia para aprender (Aplicação I= pistas verbais ou gestuais versus Aplicação II = nenhum tipo de apoio); 3) Acessar contextos educacionais e de formação (Aplicação I = ajuda física total versus Aplicação II = monitoramento); 4) Aprender habilidades de autodetermina- 
ção (Aplicação I = ajuda física total versus Aplicação II = pistas verbais ou gestuais); e 5) Aprender estratégias de autogerenciamento (Aplicação I = ajuda física total versus Aplicação II = pistas verbais ou gestuais). Cacto reconhece seu desenvolvimento ao ingressar no curso técnico e o desenvolvimento da sua autonomia no acesso as plataformas das aulas remotas, sobre a sua evolução enfatiza:

Eu tive muitas dificuldades (...) com o passar do tempo eu passei a ser comunicativo, falei mais, tive coragem de falar, de aprender. Parece que minha mãe olhou pra mim e disse "ah meu filho evoluiu". Parece que eu estou mais $100 \%$ do que eu estava antes.

Ao analisar a redução dos índices de apoio dos três domínios da Escala SIS-A, entende-se que Cacto teve um desenvolvimento satisfatório entre 0 ano de 2019 à 2020, principalmente nas habilidades de autodeterminação e autogerenciamento que pertencem as atividades de aprendizagem ao longo da vida. Atualmente Cacto faz uso da plataforma de acesso as aulas sem nenhum tipo de apoio, uma vez que suas aulas continuam sendo remotas.

De modo algum, existe a pretensão de relatar que as intervenções realizadas são as únicas responsáveis pelos resultados satisfatórios no desenvolvimento de Cacto. Há muitos fatores que podem ter contribuído para que os índices de necessidade de apoio terem mudanças tão visíveis e louváveis. Cacto tem participado ativamente de diversos projetos proporcionados pela Universidade, além dos apoios fornecidos pela equipe de gestão e profissionais do curso que frequenta. Além disso, desde 2019, bolsistas do curso de graduação em Educação Especial, tem construído estratégias e possibilidades com os estudantes com DI, do mesmo curso técnico de Cacto. Salienta-se que esse trabalho, está sendo desenvolvido no ensino remoto, o que colaborou para que Cacto tivesse apoio no acesso as plataformas da Universidade através de tutoriais e auxílios disponibilizados pelas acadêmicas. Contudo, nesse estudo como fator de maior relevância destaca-se o apoio da mãe, que sempre esteve presente e consciente de que Cacto precisa desenvolver sua autonomia, o autogerenciamento, auto advocacia e autodeterminação nas questões relacionadas ao curso técnico profissional e, também, a vida pessoal.

\section{CONCLUSÕES}

0 estudo ora relatado tinha como objetivo conhecer aspectos relacionados a Privacidade e Autonomia na vida de um Adulto com deficiência intelectual e analisar se interferem na execução das atividades de vida doméstica, atividades de vida comunitária e atividades de aprendizagem ao longo da vida. Através dos resultados, percebeuse que o planejamento e execução de atividades envolvendo aspectos desses três domínios podem ter propiciado aprimoramento de sua autonomia em atividades cotidianas, melhorando, assim, seu funcionamento no lar e na comunidade em que vive. Salienta-se que é imprescindível oferecer oportunidades de execução das tarefas para que 0 sujeito possa aprimorar suas habilidades e desempenho. Os encontros virtuais realizados durante 0 ano de 2020, também, propiciaram oportunidades do adulto expor seus sentimentos, planos futuros e desejos, contribuindo com questões relacionadas a autodeterminação e ao autogerenciamento. Gerenciando suas falas, sem a presença de terceiros, 0 adulto e a pesquisadora conseguiram constituir um espaço com privacidade e segurança. Com 0 isolamento social, imposto pela pandemia do COVID-19, as aulas do sujeito da pesquisa passaram a ser remotas, com isso ouve crescente necessidade de acesso a ambientes virtuais de aprendizagem e comunicação, a exemplo da plataforma Google Meet, inicialmente a mãe precisou estar presente para auxilia-lo no acesso, após 0 desenvolvimento de tutoriais personalizados esse acesso passou a ser realizado de forma independente, atividade caracterizada como extremamente significativa para a vida cotidiana do adulto como estudante. Também, ao analisar os níveis de apoio de atividades nos três domínios pesquisados (vida doméstica, comunitária e aprendizagem ao longo da vida) ficou evidenciado uma diminuição significativa nos índices de necessidade de apoio. Evidenciase, portanto, a importância de trabalhar atividades que desenvolvam a autonomia, autodeterminação, autogerenciamento e auto advocacia de adultos com DI, sobretudo com respeito e atenção a aspectos como privacidade. Sempre entendendo as demandas de cada sujeito, com planejamentos centrados na pessoa, nas suas necessidades e interesses pessoais, a fim de favorecer uma melhora no funcionamento no cotidiano doméstico, profissional e comunitário, focando no desenvolvimento do seu potencial, bem-estar e realização pessoal. 


\section{PRIVACIDADE E AUTONOMIA DE UM ADULTO COM DEFICIÊNCIA INTELECTUAL}

\section{REFERÊNCIAS BIBLIOGRÁFICAS}

Almeida, M.A (2004). Apresentação e análise das definições de deficiência mental proposta pela AMMR Associação Americana de Retardo Mental de 1908 a 2002. Revista de Educação. (16), 33-48. Recuperado de http://periodicos.puc-campinas.edu.br/seer/index.php/reveducacao/article/view/284/267.

American Association on Intellectual and Developmental Disabilities (AAIDD). Intellectual Disability: definition, classification and systems of supports. (11. ed.). Washington: AAIDD, 2010.

Bissoto, M. L. (2014). Deficiência Intelectual e processos de tomada de decisão: estamos enfrentando o desafio de educar para a autonomia? Educação Unisinos. 18(1), 3-12. Recuperado de http://revistas.unisinos.br/index.php/educacao/article/view/edu.2014.181.01.

Boueri, I.Z. (2010). Efeitos de um Programa Educacional para atendentes visando a independência de Jovens com Deficiência Intelectual Institucionalizados. (Dissertação de Mestrado). Programa de Pós-graduação em Educação Especial. Universidade Federal de São Carlos. São Carlos, Brasil.

Lehnhart, G. B. (2021). Gestão de Habilidades Sociais para estudantes com Deficiência Intelectual no Contexto da Educação Profissional e Tecnológica. (Projeto de Dissertação de Mestrado). Programa de Pós-Graduação em Educação Profissional e Tecnológica. Universidade Federal de Santa Maria. Santa Maria, Brasil.

La Taille, Yes de. (1999). Limites: três dimensões educacionais (2. ed). São Paulo: Ática.

Santos, M. G. (2015). Conquista da autonomia: qual o papel do reforço positivo? (Dissertação de Mestrado). Programa de Pós-graduação em Educação Pré-Escolar. Escola Superior de Educadores de Infância Maria Ulrich. Lisboa, Portugal.

Schalock, R.L., Luckasson, R., \& Tassé, M. J. (2021). Intellectual disability: Definition, diagnosis, classification, and system of supports (12. ed.). Silver Spring, AAIDD.

Thompson, J. R.; Bryant, B.R.; Campbell, E. M.; Craig, E. M.; Hughes, C.M.; Rotholz, D. A. (2004). Suports Intensity Scale user's manual. Washington, DC: AMMR.

Veltrone, A. A.; Mendes, E. G. (2009). Inclusão e fracasso escolar: o que pensam os alunos com deficiência mental? Revista Educação Especial. 22 (33), 59-72. Recuperado de https://periodicos.ufsm.br/educacaoespecial/article/view/169.

Zutião, P. (2016) Programa "Vida na Comunidade" para familiares de Jovens com Deficiência Intelectual. (Dissertação de Mestrado). Programa de Pós-graduação em Educação Especial. Universidade Federal de São Carlos. São Carlos, Brasil.

\section{NOTAS}

1 Supports Intensity Scale. Copyright@ 2015 American Association on Intellectual and Developmental Disabilities. All rights reserved. Supports Intensity Scale - Adult Version (SIS-A). A SIS está em processo de validação no Brasil através do projeto: "Adaptação e validação da escala de intensidade de apoio para crianças e adolescentes (SIS-C) com deficiência intelectual no Brasil", coordenado pelas professoras Dr ${ }^{\mathrm{a}}$ lasmin Zanchi Boueri (UFPR) e Sabrina Fernandes de Castro (UFSM). Realizado com apoio da Federação Nacional das APAEs (coordenação: Laura Valle Gontijo), com permissão para a pesquisa da American Association on Intellectual and Devopmental Disabilities (AAIDD).

20 referido projeto teve como objetivo a elaboração de um plano interventivo visando aprimorar as relações sociais em diferentes espaços acadêmicos, bem como profissionais de estudantes com deficiência intelectual. A efetivação do projeto de Lehnhart (2021) aconteceu de forma virtual, com a participação de quatro estudantes da Educação Profissional e Tecnológica, por meio de encontros semanais coletivos e individuais, com diferentes temáticas. 